\title{
Radiology. From Analogic to Digital
}

\author{
Miguel Souto Bayarri* \\ Professor of Radiology, Spain
}

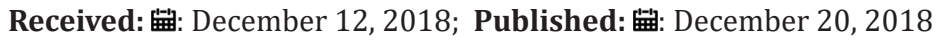

*Corresponding author: Miguel Souto Bayarri, Professor of Radiology, Spain

\section{Opinion}

For most people to talk about the digitization of diagnosis by images may seem a little far, but the truth is that we are dealing with an important issue that affects decisively the health care of the citizens. Namely, in any city, without it being necessary to visit the large capitals, there are in each hospital several scanners of computed tomography, magnetic resonances, ultrasounds, telemedicine, etcetera. A multitude of new equipment has emerged in unprecedented growth, unless we go back to the time immediately after the discovery of X-rays in 1895. The paramount importance of diagnostic imaging within hospital medicine "and out-of-hospital" Is not a novelty. It is, however, the force that these new modalities have taken and the universality of their acceptance. The problem of the current debate on this hegemony is that it tends to assume that digitization had the potential and health centers had the resources to do so. There is a loss of awareness that one day there were different options, or at least partial or apparent choice - often tinged with conservadurism - and that the arrival of the screens was an event that was not always received with enthusiasm.

Any consideration of the phenomenon of digitization cannot, therefore, be terminated without an examination, as it were, of historical facts, for example, that analogic radiography no longer represents the central part of diagnostic imaging. Nor can this controversy be disconnected from the long history of R \& D in computer technologies and medical imaging, dating back to the twentieth century, fundamentally in the United States, Europe and Japan. In fact, between 1980 and the end of the century, hospital digitization was one of the central issues faced by the research elites of the most advanced departments, and during those years occupied a stellar place among its objectives. But listening to the current debate, it is as if that had not happened, or as if it were now irrelevant. The germ of this experience is something that not everyone knows: about how the opinion favorable to the acquisition of new digital systems has been formed, not many people today remembers anything, and something should be said. This has been a vast process, with innumerable episodes and actors. But if one has to look for a key moment on that long road, from its origins to its formidable present projection, it is fair to recall the early works of Robert Fraser and Gary Barnes at the University of Alabama. A lot of water has run under bridges since 1980, when they both designed their first prototype of digital radiology.

The truth is that today it can be said that the X-rays on film have almost disappeared. Radiologists called them "plaques/plates," and the nickname was like a ring finger: they were the plaque of the first photographers. And they were also the image of the lungs and bones. In front of the radiographs and their history you can have different opinions, but nobody can deny its transcendence. What happens is that now they have become extinct and it seems that no one cares, and some even celebrate it because they say that their disappearance is an unmistakable symptom of modernization and progress. There is an aspect that continues hurting the implantation of the new techniques. Despite the importance and thrust of these technologies, the networks that support communications, and many of the computer applications, have not been adequately developed to cope with their requirements, and advances in this field have not gone hand in hand: the communication between different systems and places continues to be carried out with less advanced technologies. The divergence between the great growth of the technology of the medical image and the less progress that has been made in the infrastructures that support it (i.e., PACS), which cannot offer the necessary capacity to meet the demands of an expanding digitalization, is imposing a slow pace and lowering the quality of workflows. 
ISSN: 2574-1241

DOI: $10.26717 / B J S T R .2018 .12 .002250$

Miguel Souto Bayarri. Biomed J Sci \& Tech Res

(C) (9) This work is licensed under Creative

Submission Link: https://biomedres.us/submit-manuscript.php

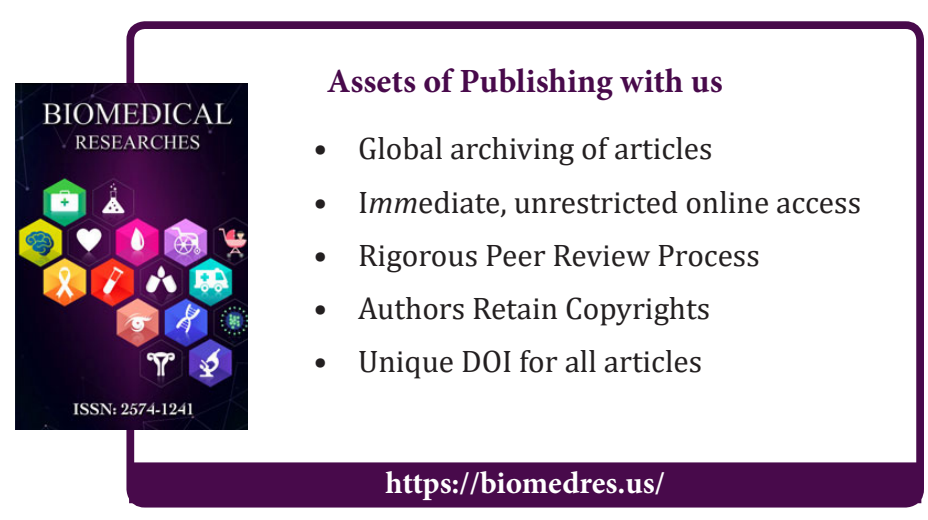

